\title{
Relationship between Primary Tumors of Nasopharyngeal Carcinoma with the Degree of Conductive Hearing Loss in Dr. Mohammad Hoesin Hospital
}

\section{Palembang}

\section{Denny Satria Utama ${ }^{*}$, Eriza ${ }^{1},{\text { Priscilla Ralahayu }{ }^{1}, \text { Erial Bahar }}^{2}$}

${ }^{1}$ Department Otorhinolaryngology Head and Neck Surgery, Faculty of Medicine, Universitas Sriwijaya/ Dr. Mohammad Hoesin General Hospital, Palembang, Indonesia

2 Department of Anatomy, Faculty of Medicine, Universitas Sriwijaya, Palembang, Indonesia

\section{A R T I C L E I N F O \\ Keywords: \\ Nasopharyngeal carcinoma \\ Conductive hearing loss \\ Audiometry \\ Early detection \\ Deafness \\ *Corresponding author: \\ Denny Satria Utama \\ E-mail address: \\ pralahayu@gmail.com}

All authors have reviewed and approved the final version of the manuscript.

https://doi.org/10.37275/bsm.v6i3.453

\begin{abstract}
A B S T R A C T
Background. Nasopharyngeal carcinoma is a malignant tumor that grows in the nasopharyngeal area with predilection in the fossa Rossenmuller and the nasopharyngeal roof adjacent to the Eustachian tube, so one of NPC's early symptoms is ear symptoms. Hearing loss is a common symptom found in people with NPC due to dysfunction of the Eustachian tube, a continuing middle ear disorder that can result in conductive hearing loss. This study aims to find out the relationship between primary tumor of NPC and the degree of conductive hearing loss at dr. Mohammad Hoesin Hospital Palembang.

Methods: This is a cross-sectional study that obtained 42 samples from the medical records at Dr. Mohammad Hoesin Hospital Palembang that met the inclusion and exclusion criteria. The study subjects collected in total sampling have been conducted audiometry examinations at the ORLHNS clinic of Dr. Mohammad Hoesin Hospital Palembang during the period January 2019 - April 2021.

Results: The proportion of hearing loss in NPC patients in this study was 30 subjects $(71.4 \%)$ with the highest proportion of hearing loss complaints being $33.3 \%$. The proportion of conductive hearing loss of nasopharyngeal carcinoma patients in the study was 33 subjects $(78.5 \%)$ right ear and 28 subjects $(66.7 \%)$ left ear. There was a significant association between the degree of the NPC primary tumor and the incidence of conductive deafness of the left ear, but there was no significant association in the right ear. There is a significant correlation between NPC primary tumors and left ear hearing thresholds at frequencies of $500 \mathrm{~Hz}$ and $4000 \mathrm{~Hz}$, but there is no significant association between the degree of NPC primary tumor and right ear hearing loss.

Conclusions: There is a significant correlation between the primary tumor of NPC and the hearing threshold of the left ear but there was no significant association in the right ear.
\end{abstract}

\section{Introduction}

Nasopharyngeal carcinoma (NPC) is a malignant tumor of the head and neck that originates from nasopharyngeal epithelial cells that are reflected in the fossa rosenmuller and the nasopharyngeal roof which is a transitional area where the cuboid epithelium turns into squamos epithelium. NPC is a malignancy in the head and neck area that has unique epidemiological characteristics, with incidences varying according to race and geographical differences. The incidence rate of NPC according to World Cancer Research journal data is 1.2 per 100,000 with the incidence of this disease more common in Southeast Asia. The highest incidence of NPC is found in Southern China at 20/100,000 cases per year. In Indonesia, the 
incidence rate of NPC ranks fifth out of all malignancies and is ranked first in head and neck malignancies. The incidence of NPC in Indonesia reached 5.6 per 100,000 or 13,084 new cases of population per year. $1,2,3$

Clinical symptoms of NPC were varied so often that an incorrect diagnosis is made. Clinical symptoms of NPC appear based on the development and expansion of the tumor itself that is divided into early and advanced symptoms. Early symptoms of NPC include symptoms of nose and ears such as complaints of ringing ears, hearing loss, nasal congestion, secret on the nose and nose bleeds. Advanced symptoms of NPC include neurological, orbital, and lymph gland symptoms, i.e. double vision, neck lumps, and persistent headaches. Most NPC patients who come for treatment to the hospital after the appearance of advanced symptoms from NPC appear.1,2,4

Diagnosis of NPC at an early stage is still difficult to obtain because of the location of the primary tumor that is difficult to reach but anatomically the location of NPC in the fossa rosenmuller adjacent to the Eustachian tube, so one of the early symptoms of NPC is ear symptoms. Ear symptoms that occur in the NPC due to enlargement or expansion of an NPC can cover the Eusthacius tube resulting in dysfunction of the Eustachian tube. Physiologically disturbed Eustachian tubes can result in impaired ventilation function, drainage of middle ear secretions, and changes in pressure in the middle ear. With these physiological changes, the middle ear has hearing loss, middle ear effusion, and tinnitus. Hearing loss caused by disturbances in the Eustachian tube in NPC is a usually conductive hearing disorder on one side of the ear. 2,4

Many theories link middle ear disorders to NPC but there are still many misdiagnosis of NPC patients with middle ear disorders so that most NPC patients are diagnosed at an advanced stage. Continued middle ear hearing loss can result in a conductive hearing loss but there have not been many studies on hearing loss in NPC patients in Indonesia itself and especially in our hospital there have been no studies examining the relationship of primary tumors (T) in NPC to degrees of hearing loss with measurements using audiometry. Complaints of hearing loss and audiometry examination are expected to show an initial diagnosis and suspicion of NPC can be known earlier. Based on the description above, this study is expected to see the relationship between primary tumor of NPC with the degree of conductive hearing loss can be known as early detection and avoid misdiagnosis to get a good prognosis for NPC patients.

\section{Methods}

This study is an analytical observational research study using a cross-sectional design that aims to analyze the relationship between primary tumor of NPC and the degree of hearing loss at Dr. Mohammad Hoesin Hospital Palembang. Data collection from medical records using total sampling in 31 patients that diagnosed with NPC and has not been done chemoradiation therapy and have been conducted audiometry examination at the ORLHNS clinic of Dr. Mohammad Hoesin Hospital Palembang during the period January 2019 - April 2021 that met the criteria of inclusion and exclusion. The inclusion criteria for this study is patients who have just been diagnosed with NPC and have not undergone chemoradiation with an audiometry examination obtained conductive hearing loss. The exclusion criteria are patients has with the perforation of the tympanic membrane. This research has an ethical exemption and was approved by the Health Research Ethics Committee of Dr.Mohammad Hoesin Palembang Hospital, No.33/kepkrsmh/2021. Ethical permits are carried out following applicable procedures and rules.

Univariate analysis is performed on the basic characteristics data of the research subject. To test the strength of the correlation between the primary tumor of NPC and the degree of conductive hearing loss, Pearson correlation tests were conducted when the data were distributed normally. When the data is not normally distributed or in the form of categorical data, Spearman correlation tests are used. To see the relationship between other variables that are categorical with the absence of hearing loss is used Chisquare test.

\section{Results}

The subjects in this study were patients who were 
newly diagnosed and had not been undergone chemoradiation therapy and there was an audiometry examination of conductive hearing loss at the ORLHNS clinic of Dr. Mohammad Hoesin Hospital Palembang and met the research criteria obtained as many as 42 patients that described in table 1 .

Table 1. Patients characteristic

\begin{tabular}{|c|c|c|c|}
\hline 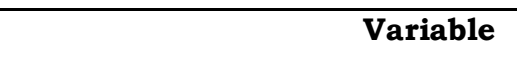 & $\mathbf{N}(42)$ & $\%$ & $\overline{\mathbf{X}} \pm$ SD \\
\hline Age & & & $43,95 \pm 14,58$ \\
\hline$\leq 20$ y.o & 4 & 9,5 & \\
\hline $21-40$ y.o & 11 & 26,2 & \\
\hline $41-60$ y.o & 24 & 57,1 & \\
\hline$>60$ y.o & 3 & 7,1 & \\
\hline \multicolumn{4}{|l|}{ Gender } \\
\hline Male & 29 & 69 & \\
\hline Female & 13 & 31 & \\
\hline \multicolumn{4}{|l|}{ Histopathology } \\
\hline WHO Type 1 & 1 & 2,4 & \\
\hline WHO Type 2 & 15 & 35,7 & \\
\hline WHO Type 3 & 26 & 61,9 & \\
\hline \multicolumn{4}{|l|}{ NPC Primary Tumor } \\
\hline T1 & 10 & 23,8 & \\
\hline T2 & 17 & 40,5 & \\
\hline T3 & 10 & 23,8 & \\
\hline $\mathrm{T} 4$ & 5 & 11,9 & \\
\hline \multicolumn{4}{|l|}{ Site of mass } \\
\hline Bilateral & 28 & 66,7 & \\
\hline Unilateral & 14 & 33,3 & \\
\hline Right side & 10 & 23,8 & \\
\hline Left side & 4 & 9,5 & \\
\hline \multicolumn{4}{|l|}{ Chief of complaints } \\
\hline Lump in the neck & 26 & 61,9 & \\
\hline Double vision & 4 & 9,5 & \\
\hline Nose bleeds & 4 & 9,5 & \\
\hline Hearing loss & 1 & 2,4 & \\
\hline Tinnitus & 2 & 4,8 & \\
\hline Headache & 2 & 4,8 & \\
\hline Nasal obstruction & 2 & 4,8 & \\
\hline Dysphagia & 1 & 2,4 & \\
\hline \multicolumn{4}{|l|}{ Hearing loss symptoms } \\
\hline Yes & 30 & 71,4 & \\
\hline Hearing loss & 14 & 33,3 & \\
\hline Tinnitus & 10 & 23,8 & \\
\hline Hearingloss and tinnitus & 3 & 7,1 & \\
\hline Ear fullness & 3 & 7,1 & \\
\hline No & 12 & 28,6 & \\
\hline
\end{tabular}

From the data obtained the average age of $53.95 \pm$ 14.58 with the most age in subjects aged in the group of 41-60 years, which is as many as 24 subjects $(57.1 \%)$. According to gender, there are more males 
than the female with 29 subjects (69\%) were male and 13 subjects (31\%) were female. Based on histopathology the most subjects in WHO type 3 as many as 26 subjects $61.9 \%$. The most degree of NPC primary tumors in the study was T2, 17 subjects were $40.5 \%$. The proportion of subjects with T1 and T3 had the same number of 10 subjects (23.8\%), while the least proportion were subjects with T4 in 5 subjects (11.9\%). The study also looked at the location of the tumor whether bilateral or unilateral, the study subjects with nasopharyngeal mass locations were found to be the most bilateral in 28 subjects (66.7\%) compared to unilateral in 14 subjects $33.3 \%$ that found on the right side in 10 subjects (23.8\%) and left in 4 subjects (9.5\%).

From the data obtained the most complaints are lumps in the neck in 26 subjects (61.9\%), followed by the second largest proportion of chief complaints is double vision and nose bleeds in 4 subjects each $(9.5 \%)$, ringing ears, headaches, and nasal obstruction with a proportion of 2 subjects each (4.8\%) and complaints with the least proportion in the study were complaints of dysphagia and hearing loss obtained by 1 subject (2.4\%). This study also looked at complaints obtained by ear through the history of the disease. Of the history of the disease, 30 subjects (71.4\%) had ear complaints and 12 subjects $(28.6 \%)$ had no ear complaints. Among the study subjects who experienced complaints of hearing loss, the proportion of hearing loss of 14 subjects was (33.3\%), followed by tinnitus in 10 subjects $(23.8 \%)$, then at least in hearing loss and tinnitus and ear fullness of 3 subjects each (7.1\%).

Table 2. Ear examination result

\begin{tabular}{|l|c|c|}
\hline \multicolumn{1}{|c|}{ Variable } & N & \% \\
\hline Conductive hearing loss & & $78,6 \%$ \\
\hline Right ear & 33 & $66,7 \%$ \\
\hline Left ear & 28 & \\
\hline Right ear hearing loss (N=33) & & 54,5 \\
\hline Mild & 18 & 18,2 \\
\hline Moderate & 6 & 24,2 \\
\hline Moderate - severe & 8 & 3,0 \\
\hline Severe & 1 & \\
\hline Left ear hearing loss (N=28) & & 42,9 \\
\hline Mild & 12 & 35,7 \\
\hline Moderate & 10 & 14,3 \\
\hline Moderate - severe & 4 & 7,1 \\
\hline Severe & 2 & \\
\hline Tympanometry & & \\
\hline Right ear & & 9,5 \\
\hline Type A & 4 & 59,5 \\
\hline Type B & 25 & 31,0 \\
\hline Type C & 13 & \\
\hline Left Ear & & 23,8 \\
\hline Type A & 10 & 59,5 \\
\hline Type B & 25 & 16,7 \\
\hline Type C & 7 & \\
\hline & & \\
\hline
\end{tabular}

In table 2, an overview of the characteristics of the results of audiometry and tympanometry examinations conducted. Based on the distribution of conductive hearing loss in NPC patients, 33 subjects with conductive hearing loss (78.6\%) had a conductive loss of the right ear and 28 subjects (66.7\%) had left ear conductive hearing loss. Based on the distribution of the degree of right ear conductive hearing loss in NPC patients obtained the most in mild degrees in 18 subjects (54.5\%), moderate conductive impairment as many as 6 subjects (18.2\%), moderate-severe degrees were 8 subjects $(24.2 \%)$ and in severe degrees, there 
was only 1 subject (3\%). Based on conductive hearing loss in the left ear, there are also the most in mild degrees in 12 (42.9\%), moderate degrees in 10 subjects $(35.7 \%)$, moderate-severe degrees in 4 subjects $(14.3 \%)$ and severe degrees is 1 subject (3\%). On the examination of audiometry in the left ear, there are 12 subjects (42.9\%), with each having moderate degrees of hearing loss in 10 subjects (35.7\%), moderate-severe degrees in 4 subjects (14.3\%), and severe degrees there are 2 subjects $(7.1 \%)$. The study also looked at the characteristics of tympanometry in the right and left ears of NPC patients. Characteristics of ear examination results from this study with the results of tympanometry interpretation in the right ear were found at most in type $B$ as many as 25 subjects (59.5\%), type $\mathrm{C}$ there were 13 subjects (31\%), and type A only found 4 subjects $(9.5 \%)$. The proportion in the left ear tympanometry also in type B as many as 25 subjects (59.5\%), type $\mathrm{C}$ in 7 subjects (16.7\%) and type A there were 10 subjects (23\%).

Table 3. Primary tumor and hearing threshold

\begin{tabular}{|l|c|c|c|}
\hline \multicolumn{1}{|c|}{ Hearing threshold } & Means \pm SD & Median & Normality test $^{\mathbf{a}}$ \\
\hline Primary tumor (T) & $2,24 \pm 0,96$ & 2 & $<0,001$ \\
\hline Right ear & & & 0,021 \\
\hline $250 \mathrm{~Hz}$ & $38,4 \pm 13,8$ & 37,5 & 0,582 \\
\hline $500 \mathrm{~Hz}$ & $38,0 \pm 13,9$ & 35 & 0,029 \\
\hline $1000 \mathrm{~Hz}$ & $39,4 \pm 18,1$ & 37,5 & 0,036 \\
\hline $2000 \mathrm{~Hz}$ & $49,2 \pm 23,3$ & 45 & 0,063 \\
\hline $4000 \mathrm{~Hz}$ & $57,4 \pm 26,6$ & 52,5 & 0,079 \\
\hline $6000 \mathrm{~Hz}$ & $56,3 \pm 27,8$ & 55 & $<05$ \\
\hline $8000 \mathrm{~Hz}$ & & & 0,001 \\
\hline Left ear & $37,0 \pm 15,7$ & 32,5 & 0,001 \\
\hline $250 \mathrm{~Hz}$ & $34,3 \pm 15,1$ & 30 & 0,008 \\
\hline $500 \mathrm{~Hz}$ & $35,2 \pm 16,2$ & 35 & 0,001 \\
\hline $1000 \mathrm{~Hz}$ & $37,4 \pm 15,4$ & 30 & 0,017 \\
\hline $2000 \mathrm{~Hz}$ & $42,0 \pm 19,3$ & 37,5 & 0,007 \\
\hline $4000 \mathrm{~Hz}$ & $46,6 \pm 21,6$ & 47,5 & 0,021 \\
\hline $6000 \mathrm{~Hz}$ & $45,4 \pm 23,5$ & 45 & \\
\hline $8000 \mathrm{~Hz}$ & & & \\
\hline
\end{tabular}

*p-value normality test with Shapiro-Wilk

Table 3 shows the characteristics of the hearing threshold for each frequency in NPC patients. All hearing threshold data in each frequency in the right ear with variable primary tumors are not normally distributed with $\mathrm{p}<0.05$. On the left ear hearing threshold variables at normally distributed frequencies of $500 \mathrm{~Hz}, 4000 \mathrm{~Hz}, 6000 \mathrm{~Hz}$, and $8000 \mathrm{~Hz}$. In addition to these four variables, all hearing threshold variables are not a normal distribution. So we use the Spearman test to find out the correlation between the primary tumor of the NPC and the hearing threshold in each frequency. 
Table 4. Correlation between NPC primary tumor with hearing threshold

\begin{tabular}{|l|c|c|}
\hline \multicolumn{1}{|c|}{ Hearing threshold } & Correlation value (r) & p-value* \\
\hline Right Ear & & 0,103 \\
\hline $250 \mathrm{~Hz}$ & 0,255 & 0,382 \\
\hline $500 \mathrm{~Hz}$ & $0,138,264$ \\
\hline $1000 \mathrm{~Hz}$ & 0,176 & 0,760 \\
\hline $2000 \mathrm{~Hz}$ & 0,049 & 0,321 \\
\hline $4000 \mathrm{~Hz}$ & 0,157 & 0,810 \\
\hline $6000 \mathrm{~Hz}$ & 0,038 & 0,367 \\
\hline $8000 \mathrm{~Hz}$ & 0,143 & 0,399 \\
\hline Left Ear & & 0,026 \\
\hline $250 \mathrm{~Hz}$ & 0,134 & 0,063 \\
\hline $500 \mathrm{~Hz}$ & 0,342 & 0,104 \\
\hline $1000 \mathrm{~Hz}$ & 0,289 & 0,021 \\
\hline $2000 \mathrm{~Hz}$ & 0,254 & 0,096 \\
\hline $4000 \mathrm{~Hz}$ & 0,356 & 0,069 \\
\hline $6000 \mathrm{~Hz}$ & 0,260 & 0,283 \\
\hline $8000 \mathrm{~Hz}$ & & \\
\hline
\end{tabular}

*Spearman Correlation Test

Based on table 4 shows the relationship between the enlargement of the NPC primary tumor and the hearing threshold for each frequency from table 3 , it has been known that the distributed data is abnormal, so the correlation test between the degree of enlargement of the NPC primary tumor with the hearing threshold using the Spearman test. There is a significant correlation between NPC primary tumors and left ear hearing thresholds at frequencies $500 \mathrm{~Hz}$ and $4000 \mathrm{~Hz}$. Both have weak correlation strength (r: 0.20 - 0.40) and in the direction, the larger the primary tumor, the greater the hearing threshold in audiometry. While in the right ear there is no correlation between enlargement of the primary tumor and hearing threshold.

Table 5. Association between NPC primary tumor with right ear conductive hearing loss

\begin{tabular}{|c|c|c|c|c|c|c|c|}
\hline \multirow{3}{*}{$\begin{array}{c}\text { NPC } \\
\text { primary } \\
\text { tumor }(T)\end{array}$} & \multicolumn{6}{|c|}{ Right ear conductive hearing loss } & \multirow{3}{*}{$\mathbf{P}$ value } \\
\hline & \multicolumn{2}{|c|}{ Yes } & \multicolumn{2}{|c|}{ No } & \multicolumn{2}{|c|}{ Total } & \\
\hline & $\mathrm{n}$ & $\%$ & $\mathrm{n}$ & $\%$ & $\mathrm{n}$ & $\%$ & \\
\hline $\mathrm{T} 1$ & 8 & 19 & 2 & 4,8 & 10 & 23,8 & \multirow{4}{*}{0,207} \\
\hline T2 & 14 & 33,4 & 3 & 7,1 & 17 & 40,5 & \\
\hline T3 & 9 & 21,4 & 1 & 2,4 & 10 & 23,8 & \\
\hline T4 & 2 & 4,8 & 3 & 7,1 & 5 & 11,9 & \\
\hline
\end{tabular}

a Chi-square test

Table 6. Association between NPC primary tumor with left ear conductive hearing loss

\begin{tabular}{|c|c|c|c|c|c|c|c|}
\hline \multirow{2}{*}{$\begin{array}{c}\text { NPC } \\
\text { Primary } \\
\text { Tumor } \\
(\mathbf{T})\end{array}$} & \multicolumn{6}{|c|}{ Left ear conductive hearing loss } & \multirow{2}{*}{ P value } \\
\cline { 2 - 8 } & $\mathrm{n}$ & $\%$ & $\mathrm{n}$ & $\%$ & $\mathrm{n}$ & $\%$ & \\
\hline $\mathrm{T} 1$ & 7 & 16,7 & 3 & 7,1 & 10 & 23,8 & \\
\hline $\mathrm{T} 2$ & 7 & 16,7 & 10 & 23,8 & 17 & 40,5 \\
\hline $\mathrm{T} 3$ & 9 & 21,4 & 1 & 2,4 & 10 & 23,8 \\
\hline $\mathrm{T} 4$ & 5 & 11,9 & 0 & 0 & 5 & 11,9 & \\
\hline
\end{tabular}

a Chi-square test 
Based on table 5 groups with T2 NPC primary tumor had the most frequency in the incidence of right ear conductive hearing loss as many as 14 subjects (33.4\%), T3 in 9 subjects (21.4\%), T1 in 8 subjects (19\%) and only 2 subjects (4.8\%) in T4. There was no significant association between the degree of the NPC primary tumor and the incidence of conductive hearing loss of the right ear with the result of P-value 0,207. Based on table 6 in the group with primary tumor degrees T1 and T2 groups were obtained as many as 7 subjects (16.7\%), in the T3 group there were 9 subjects and in T4 as many as 5 subjects (11.9\%). The P-value between the degree of the NPC primary tumor and the incidence of conductive hearing loss of the left ear is 0.008 so that there is a significant association between the degree of the NPC primary tumor and the occurrence of conductive hearing loss of the left ear.

Table 7. Association between NPC primary tumor site with right ear conductive hearing loss

\begin{tabular}{|c|c|c|c|c|c|c|c|c|c|c|c|c|c|}
\hline \multirow{4}{*}{$\begin{array}{l}\text { Primary tumor } \\
\text { site in the right } \\
\text { nasopharynx }\end{array}$} & \multicolumn{12}{|c|}{ Right ear hearing loss } & \multirow{4}{*}{$\mathbf{P}$} \\
\hline & \multirow{2}{*}{\multicolumn{2}{|c|}{$\begin{array}{l}\text { No conductive } \\
\text { hearing loss }\end{array}$}} & \multicolumn{8}{|c|}{ Conductive hearing loss } & \multirow{2}{*}{\multicolumn{2}{|c|}{ Total }} & \\
\hline & & & \multicolumn{2}{|c|}{ Mild } & \multicolumn{2}{|c|}{ Moderate } & \multicolumn{2}{|c|}{$\begin{array}{c}\text { Moderate } \\
\text { severe }\end{array}$} & \multicolumn{2}{|c|}{ Severe } & & & \\
\hline & $\mathrm{n}$ & $\%$ & $\mathrm{n}$ & $\%$ & $\mathrm{n}$ & $\%$ & $\mathrm{n}$ & $\%$ & $\mathrm{n}$ & $\%$ & $\mathrm{n}$ & $\%$ & \\
\hline Yes & 5 & 11,9 & 18 & 42,9 & 6 & 14,3 & 8 & 19 & 1 & 2,4 & 38 & 90,5 & 0,007 \\
\hline No & 4 & 9,5 & 0 & 0 & 0 & 0 & 0 & 0 & 0 & 0 & 4 & 9,5 & \\
\hline
\end{tabular}

Table 8. Association between NPC primary tumor site with left ear conductive hearingloss

\begin{tabular}{|c|c|c|c|c|c|c|c|c|c|c|c|c|c|}
\hline \multirow{4}{*}{$\begin{array}{c}\text { Primary } \\
\text { tumor site } \\
\text { in the left } \\
\text { nasophary } \\
n x\end{array}$} & \multicolumn{12}{|c|}{ Left ear hearing loss } & \multirow{4}{*}{$\mathbf{P}$} \\
\hline & \multirow{2}{*}{\multicolumn{2}{|c|}{$\begin{array}{c}\text { No Conductive } \\
\text { Hearing Loss }\end{array}$}} & \multicolumn{8}{|c|}{ Conductive hearing loss } & \multirow{2}{*}{\multicolumn{2}{|c|}{ Total }} & \\
\hline & & & \multicolumn{2}{|c|}{ Mild } & \multicolumn{2}{|c|}{ Moderate } & \multicolumn{2}{|c|}{$\begin{array}{l}\text { Moderat } \\
\text { e severe }\end{array}$} & \multicolumn{2}{|c|}{ Severe } & & & \\
\hline & $\mathrm{n}$ & $\%$ & $\mathrm{n}$ & $\%$ & $\mathrm{n}$ & $\%$ & $\mathrm{n}$ & $\%$ & $\mathrm{n}$ & $\%$ & $\mathrm{n}$ & $\%$ & \\
\hline Yes & 6 & 14,3 & 10 & 23,8 & 10 & $\begin{array}{c}23, \\
8\end{array}$ & 4 & 9,5 & 2 & 4,8 & 32 & 76,2 & 0,003 \\
\hline No & 8 & 19 & 2 & 4,8 & 0 & 0 & 0 & 0 & 0 & 0 & 10 & 23,8 & \\
\hline
\end{tabular}

a Chi-square test

From table 7 there is a significant association found between the location of the tumor in the right ear and conductive hearing loss in the right ear with a result of $\mathrm{P}=0.007$. Based on table 8, we looked at the association of the location of the NPC primary tumor with the degree of conductive hearing loss in the left ear with the result of a significant association between the location of the tumor in the left ear with conductive hearing loss in the left ear.

Table 9. Association between NPC primary tumor site with right ear tympanometry

\begin{tabular}{|c|c|c|c|c|c|c|c|c|c|}
\hline \multirow{3}{*}{$\begin{array}{c}\text { Primary } \\
\text { tumor site in } \\
\text { the right } \\
\text { nasopharynx }\end{array}$} & \multicolumn{6}{|c|}{ Right Ear Tympanometry } & \multirow{3}{*}{ P value } & \multirow{3}{*}{$\mathbf{r}^{\mathbf{b}}$} & \multirow{3}{*}{$\mathbf{P R}$} \\
\hline & \multicolumn{2}{|c|}{ Abnormal } & \multicolumn{2}{|c|}{ Normal } & \multicolumn{2}{|c|}{ Total } & & & \\
\hline & $\mathrm{n}$ & $\%$ & $\mathrm{n}$ & $\%$ & $\mathrm{n}$ & $\%$ & & & \\
\hline No & 1 & 2,4 & 3 & 7,1 & 4 & 9,5 & 0,001 & 0,500 & 3,895 \\
\hline
\end{tabular}

aChi-Square test; bLambda Correlation test (Right Tympanometry Dependent) 
Table 10. Association Between NPC primary tumor site with left ear tympanometry

\begin{tabular}{|c|c|c|c|c|c|c|c|c|c|}
\hline \multirow{3}{*}{$\begin{array}{c}\text { Primary } \\
\text { Tumor Site } \\
\text { in the Left } \\
\text { Nasopharynx }\end{array}$} & \multicolumn{6}{|c|}{ Left Ear Tympanometry } & \multirow{3}{*}{ P value } & \multirow{3}{*}{$\mathbf{r}^{\mathbf{b}}$} & \multirow{3}{*}{$\mathbf{P R}$} \\
\hline & \multicolumn{2}{|c|}{ Abnormal } & \multicolumn{2}{|c|}{ Normal } & \multicolumn{2}{|c|}{ Total } & & & \\
\hline & $\mathrm{n}$ & $\%$ & $\mathrm{n}$ & $\%$ & $\mathrm{n}$ & $\%$ & & & \\
\hline Yes & 31 & 73,8 & 1 & 2,4 & 32 & 76,2 & & & \\
\hline
\end{tabular}

aChi-Square test; bLambda correlation test (left tympanometry dependent)

Based on tables 9 and 10 shows the association of the location of the right and left side NPC tumors with the results of right ear tympanometry examination obtained from 38 primary tumors of NPC on the right side there were 37 subjects (88.1\%) who showed abnormal tympanometry results (type B or type C) with a result of $\mathrm{p}=0.001$ And NPC tumor on the left side of the nasopharynx with typanometry examination in the left ear found a significant correlation between the incidence of tumors in the left ear with the results of left ear tympanometry with the result of $\mathrm{P}=<0.001$. There is a strong and unidirectional correlation between the location of the NPC tumor side with the results of tympanometry. In this study, tumors in the right ear were 3.9 times at risk for causing abnormal results in right tympanometry and tumors in the left ear 9.7 times at risk for causing abnormal results in left tympanometry.

\section{Discussion}

Based on the age distribution in this study from 42 samples obtained the most study subjects aged in the group of 41-60 years, which is $57.1 \%$ with an average age of $53.95 \pm 14.58$. In the distribution based on gender obtained male amounted to 29 samples (69\%) and female 13 samples (31\%). It is following the study from Farhat et al., of 98 NPC patients obtained the most age group also at the group of 41-60 years in 56 patients $(57.1 \%)$ and obtained male as many as 73 patients $(74.5 \%)$ and the rest were female 25 patients $(25.5 \%)$. Based on a previous study by Kurnia et al., also obtained the occurrence of NPC cases in males and females is 1.57: 1 with the most age in the age group of 41-60 years as much as $44.44 \%$. The study by Edris et al., obtained also subjects at the age of 41-60 years with the number of 29 patients and of the gender also obtained male more than female in 55 patients $(67.1 \%)$ of the 82 patients. NPC mostly occurs in the $4^{\text {th }}$ and $5^{\text {th }}$ decades of life, this may be explained by the pathogenesis of NPC due to chronic processes. Normal cells transform into cancer cells due to spontaneous mutations or induction of carcinogens. Some of the factors that cause NPC are often found in males, such as smoking habits, exposure to wood dust, irregular lifestyle, and diet that resulted in a male being more often exposed to carcinogens. This explains slightly that NPC is influenced by gender. 4,5,6

Based on this study subjects with WHO histopathology type 1 are least found, which is $2.4 \%$. The largest proportion of subjects is in WHO type 3, which is $61.9 \%$, while WHO type 2 is $35.7 \%$. Similar to the previous study by Kurnia et al., in Aceh obtained the most is WHO type 3 undifferentiated carcinoma as many as 32 patients (44.4\%), Non-keritinizing cell carcinoma as many as 24 patients (33.3\%) and Keritinizing cell carcinoma as many as 16 patients $(22.2 \%)$. While the study by Edris et al., in Sudan obtained the most in histopathology WHO type 2 in 62 patients $(75.6 \%)$ and WHO type 3 in 20 patients $(24.4 \%)$. Based on the distribution of NPC primary tumors with the most conductive hearing loss in T2, which is 17 subjects (40.5\%), while the least proportion were subjects with primary tumors $\mathrm{T} 4$ which is 5 subjects (11.9\%). Similarly, Wang et al., found the most primary tumor enlargement at T2 degrees in 32 subjects followed by $\mathrm{T} 1$ as many as 31 subjects from 101 subjects. The study by Haleshappa et al., also obtained the most tumor data in T2 in 48 patients 
(33.6\%) followed by $\mathrm{T} 4$ in 36 patients $(25.2 \%)$. This study also found the location of NPC primary tumors in the nasopharynx was found mostly bilateral as many as 28 subjects $(66.7 \%)$ compared to unilateral right in 10 subjects $(23.8 \%)$ and left side only in 4 subjects 9.5\%. The previous study showed the same results on the nasopharyngoscopy examination obtained there is $60 \%$ bilateral mass in the nasopharynx, while the unilateral mass on the right $22.86 \%$ and the left $17.14 \%$. Nasopharyngeal mass initially occurs on one side but with time travel NPC events can occur on both sides of the nasopharynx. This may be due to ignorance of the presence of a mass in the nasopharynx area so that resulting the mass has occurred on both sides. $5,6,7,8$

The most widely chief complaint clinical symptoms that make patients come for treatment such as a lump in the neck, hearing loss, nose bleeds, double vision and others. Based on clinical symptoms in NPC patients in this study the most chief complaints were lumped in the neck, which is $61.9 \%$, followed by double vision and nose bleeds in 9.5\%, tinnitus, headaches and nasal obstruction with a proportion of $4.8 \%$ each. And the complaints with the least proportion in the study were dysphagia and hearing loss of $2.4 \%$ each. The study conducted by Kanno et al., also obtained the most complaints is lumps in the neck in $44 \%$ followed by ear complaints in $38 \%$ and nose complaints in $24 \%$. While the study conducted at Dr. Mohammad Hoesin Hospital Palembang previously by Dewolo et al., obtained the most complaints were nasal obstruction in $49.09 \%$ and at least with complaints of dysphagia in $1.82 \%$ while ear complaints were only obtained in $3,76 \%$ samples. NPC spreads through the lymph node of the neck, lymphatic flow from fossa rossenmuller flows into Rouvier's node all the way to the retropharyngeal chamber and continues to the upper neck lymph nodes, so the appearance of lumps in the neck is often a clinical symptom of NPC. And the location of the lump in the neck is very easy to see, the patient will be faster to find out if there is a lump on the neck, while in the area inside the nose and ears the patient can not see it directly so that the patient only realizes when there are complaints in the area. 9,10

In this study found $71.4 \%$ of patients has ear complaints while subjects who did not experience hearing loss was $28.6 \%$. Among the study subjects who experienced complaints of hearing loss, the most proportion of hearing loss, which was 33.3\%, followed by tinnitus in $23.8 \%$, at least in hearing loss and tinnitus and ear fullness each as much as $7.1 \%$. In the study by Jayalie, et al., obtained the most ear complaints are bilateral ear disorders which are in $39.5 \%$ and tinnitus as much as $34.1 \%$. In the study by Dawolo et al., the most are tinnitus complaints were $21.82 \%$ and hearing loss in $1.82 \%$. In the study conducted to find out early an NPC through the symptoms of OME by Kuen Yao Ho et al., obtained from 87 OME patients, 85 cases (97.7\%) with hearing loss, ear fullness in 61 cases (70.1\%), tinnitus 43 cases (49.4\%) and sounds like water in the ears in 5 cases $(5.7 \%)$. This is because if there is a mass in the nasopharynx there can be impaired eustachius tube function which then occurs middle ear effusion due to tumor infiltration in the nasopharynx that can damage cartilage, muscle, musculature tensor and levator veli palatini. So that the occurrence of ear disorders such as ear fullness, hearing loss and tinnitus becomes a complaint in the ears. 10,11,12

This study obtained results of audiometry examination and timpanometry. Based on the distribution of conductive hearing loss in NPC patients obtained 33 conductive hearing loss of the right ear and 28 conductive hearing loss in the left ear. Based on the distribution of the degree of conductive hearing loss of the right ear in NPC patients obtained the most in mild degrees in 18 ears (54.5\%) and conductive hearing loss in the left ear was also obtained the most in mild degrees of 12 right ears (42.9\%). Characteristics of ear examination results from this study the results of tympanometry is type $\mathrm{B}$ in the right ear were found to be at most $59.5 \%$. While the proportion of subjects with tympanometry type $\mathrm{C}$ in the right ear is $31 \%$ and the interpretation of tympanometry type $\mathrm{A}$ in the right ear is $9.5 \%$. In this study found tympanometry type B in the left ear was found to be the most in $59.5 \%$ of patients. While the proportion of subjects with tympanometry type A in the left ear, which is $23.8 \%$ and the interpretation of tympanometry type $\mathrm{C}$ in the left ear is $16.7 \%$. Based on the study conducted by 
Wahyuni et al., at Palembang obtained patients with the most patients with moderate conductive hearing loss as much as $20 \%$ and followed by mild conductive hearing loss of $13.3 \% .{ }^{13,14}$

This is following the literature that most NPC patients experience a conductive hearing loss with varying degrees according to the infiltration of tumor mass in the nasopharynx, it is following the results of audiometry and tympanometry, which is due to the occurrence of disorders of tubal function due to infiltration of tumors in the nasopharynx. Disruption of tuba function causes the effusion of the middle ear. The degree of hearing disorders in patients is mostly mild and moderate degrees, this is because of the weight of the process that occurs in the middle ear so that the conduction process can still run. It can also happen because the patient may have a new impairment of tubal function. An impaired tubal function that affects the middle ear or causes middle ear effusion, resulting in hearing loss, which is conductive from audiometry examination and type B and C tympanometry. 1,2,14

Through the analysis, we found that there is a correlation between the degree of enlargement of the NPC primary tumor with the hearing threshold (P $<0.05$ ) but only found significantly in the left ear at the frequency of $500 \mathrm{~Hz}$ and $4000 \mathrm{~Hz}$, so the larger the tumor the greater the threshold of hearing. This is the same as the study conducted by Al-Rajhi et al., who also analyzed 272 patients who were late to the diagnosis of NPC with hearing loss, 129 people had hearing loss, while of the 35 people who were not late diagnosed with NPC with hearing loss, 9 people had decreased hearing. Analysis showed $\mathrm{p}<0.05$ which means hearing loss affects the late diagnosis of NPC. Conductive hearing loss is the most common NPC patient occurs in the ear on one side but the increase in the degree of tumor or late management can make the mass greater and can cause disturbances in both ears. Based on the bivariate analysis to see the relationship between the degree of NPC primary tumor and the incidence of conductive hearing loss there is a significant association in the left ear statistically $(\mathrm{P}=$ 0.007), while in the right ear there is no statistically significant association $(P=0.207)$. In the left ear following an existing study that the presence of NPC primary tumors in the fossa rosenmuller can result in conductive hearing loss, this is due to the location of the tumor near the eustachian tube that results in conductive hearing loss so that there is a relationship between the primary tumor and the occurrence of conductive hearing loss. But in this study in the right ear, we did not get a significant relationship may be due to the small number of samples or variations in the degree of tumor in the right ear is uneven so that the results obtained no significant relationship. 2,14,15

The relationship of the side location of the NPC primary tumor with the degree of conductive hearing loss is obtained in the right and left ear. In this study, the most hearing loss of mild hearing loss, in the left ear was obtained the most in mild and moderate degrees of hearing loss. This is following another study that there is a relationship between the occurrence of conductive hearing loss to the side of the tumor. This study also looked at the relationship between the location of the primary tumor and the results of tympanometry examination in the ear that obtained in the right and left ear has a strong and unidirectional relationship. Similar to the results of research conducted by Asroel et al., they concluded tympanometry has a strong correlation with the location of tumors in NPC patients. This tympanometry examination is an objective examination of the state of the middle ear and is useful for assessing the function of the middle ear so that the presence of middle ear disorders will provide an abnormal picture of tympanometry, so that if there is a disfunction in the middle ear can be detected assisted from tympanometry examination. 2,14,16

\section{Conclusion}

There was a significant correlation between NPC primary tumors and left ear hearing thresholds at frequencies of $500 \mathrm{~Hz}$ and $4000 \mathrm{~Hz}$. The most right ear conductive hearing loss is mild degrees in 18 subjects $(42.9 \%)$, the left ear received the mildest conductive hearing loss and moderate degrees in 10 subjects each $(23.8 \%)$. There was a significant association between the degree of the NPC primary tumor and the incidence of conductive hearing loss of the left ear. There is a strong and unidirectional relationship at the location of 
the NPC primary tumor with the results of tympanometry and audiometry examination. The proportion of hearingloss in NPC patients in the study was $71.4 \%$ and the proportion of conductive hearing loss of NPC patients in the study was $78.5 \%$ on the right ear and $66.7 \%$ on the left ear.

\section{References}

1. Wei WI, Chua DTT. Nasopharyngeal carcinoma. In: Johnson JT, Rosen CA, editors. Bailey's Head \& Neck Surgery Otolaryngology, 5th Ed. Philadelphia. Lippincott Williams \& Wilkins. 2014; 187597.

2. Adham M, Mangunkusumo E, Mayangsari ID. Nasopharyngeal Tumor. In Mangunkusumo E, Balfas H, Hermani B, eds. Comprehensive Textbook of Ear, Nose, Throat Head-neck. Jakarta. EGC. 2019: 499509. [in Indonesian]

3. Salehiniya H, Mohammadian M, Mahdavifar N. Nasopharyngeal cancer in the world: epidemiology, incidence, mortality and risk factors. World Cancer Res J. 2018; 5(1): 1-8.

4. Farhat, Adham M, Dewi YA, Indrasari SR. Nasopharyngeal carcinoma. EGC. Jakarta. 2020. [in Indonesian]

5. Kurnia B, Kamarlis RK, Kamal FK. Characteristic of nasopharyngeal carcinoma in Aceh 2016-2017. International Journal of Nasopharyngeal Carcinoma. 2019; 1(1): 2429.

6. Eldris A, Mohamed MA, Mohamed NS, Siddig EE. Molecular detection of Epstein- Barr virus in nasopharyngeal carcinoma among Sudanese population. Infectious Agents and Cancer. 2016; 11(55): 1-5.

7. Wang KH, Austin SA, Chen SH, Sonne DC, Gurushanthaiah D. Nasopharyngeal Carcinoma Diagnostic Challenge in a Nonendemic Setting: Our Experience with 101 Patients. Perm J. 2017; 21: 16-180.

8. Heleshappa RA, Thanky AH, Lakshmaiah K, Kanakasetty GB, Dasappa L, Jacob. Epidemiology and outcomes of nasopharingeal carcinoma: Experience from a regional cancer center in southern India. The south Asian Journal of cancer. 2017; 6(3): 122-124.

9. Kanno M, Narita N, Fujimoto Y, Wakisaka N, Yoshizaki T, Kodaira T, et al. Third epidemiological analysis of nasopharyngeal carcinoma in the Central Region of Japan from 2006 to 2015. Cancers. 2019; 11(8): 1180 .

10. Dawalo AP, Utama DS. Clinical profile of nasopharyngeal carcinoma in the Department of ENT Dr. Mohammad Hoesin Hospital Palembang from 2014-2015. Majalah Kedokteran Sriwijaya. 2017; 49(1): 1-9. [in Indonesian]

11. Ho KY, Lee KW, Chai CY, Kuo WR, Wang HM, Chien CY. Early recognition of Nasopharyngeal cancer in adults with only otitis media with effusion. J Otolaryngol Head Neck Surg. 2008; 37(3): 362-5.

12. Jayalie VF, Paramitha MS, Jessica, Liu CA, Ramadianto AS, Trimartani, Adham M. Profile of nasopharingeal carcinoma in Dr. Cipto Mangunkusumo national hospital. eJKI. 2016; 3(4): 156-162.

13. Wahyuni I, Utama DS, Ghanie A. The effect of carboplatin chemotherapy regulation on hearing function in patient of nasopharyngeal carcinoma. Internasional Journal Of Nasopharyngeal Carcinoma.2019; 2(1): 61-6.

14. Low WKC, Rangabashyam M. Ear related issues in patients with nasopharyngeal carcinoma. Carcinogenesis, diagnosis and molecular targeted treatment for nasopharyngeal carcinoma. Singapore. InTech. 2012: 155-172.

15. Al-Rajhi N, El-sebaie M, Khafaga Y. AlZahrani. Mohamed G, Al-Amro A. Nasopharyngeal carcinoma in Saudi Arabia: clinical presentation and diagnostic delay. Eastern Mediterranean Health Journal.2009; 15(5): 1301-1307. 
16. Asroel HA, Hidayat B, Adenan A, Hafni.

Correlation between tympanogram images with tumor location and stage in patients newly diagnosed with nasopharyngeal carcinoma. J Indon Med Assoc. 2012; 62(3):

102-106. [in Indonesian] 